Discourse and Communication for Sustainable Education, vol. 5, pp. 38-48, 2014

\title{
A Case Study of ESD Implementation: Signs of Sustainable Leadership
}

\author{
Dzintra Iliško and Yelena Badyanova \\ Daugavpils University, Latvia
}

\begin{abstract}
This article presents a case study of two schools that were identified as a result of UNESCO associated schools survey as cases of sustainable leadership and governance. The aim of the study is to present the two cases that were crystalized in the survey carried out at end of the United Nations' Decade of Education for Sustainable Development (2005-2014). Prior to the in-depth study of two schools, the authors have carried out a survey of the heads and deputy heads of 26 UNSECO associated schools in Latvia on how schools are succeeding in improving educational outcomes, school development, cooperation with multiple stakeholders, and innovation. The authors have carried out semi structured interviews with the heads and deputy heads of two schools on the following questions: How has ESD updated and improved educational purposes and outcomes in your school? Does ESD improve test scores and/or achieve other desired outcomes? How does ESD help to improve and enrich school curriculum development in your school? How does ESD guide students to have the knowledge, skills and values to care for and solve the sustainable development issues that arise in your school? How does ESD help to strengthen the partnerships between schools and other stakeholders, including the surrounding community? How does ESD promote innovation in the teaching-learning conceptual framework?
\end{abstract}

Keywords: sustainable leadership, value-based education, wise leadership

In a number of significant international documents (UNESCO, 2005; UNESCO, 2006; UNESCO, 2010) it has been recognized that education plays a crucial role in achieving sustainable development by promoting values and attitudes required for positive social transformation. In the DESD conference in Nagoya in 2014 it has been emphasized that full implementation of sustainability is needed in school curriculum, both in the context and in pedagogical approaches (UNESCO, 2014). Particular emphasis was payed to quality insurance that aims at improving teaching and learning. Enhancement of quality insurance is based on systematic thinking and continuous improvement (Holm, Sammalisto, Grindstead, Vuorisalo, 2015). As many authors (Cameron \& Quinn, 2006; Schein, 2004, Sterling, 2005; Iliško, Skrinda, Mičule, 2014) assert, in order for the sustainability to become a whole school approach, the change of a culture of school is needed next to methods, tools and approaches. This includes changes in values and ways of thinking. 
Numerous research has been written on sustainable leadership in pursuing a vision of a sustainable school (Duignan \& Bezzina, 2006; Hargreaves \& Fink, 2007) that is grounded in a shared vison, decision making by acknowledging people's potential. It requires a paradigm shift and a system approach to meet the demands of changing school. Sustainable leadership in this article is defined as a long term strategy of the development of school based on moral purpose and ensuring education for all, characterized by such features as: having passion for continuous improvement, keeping sound balance between the best of the past tradition and innovations, thinking in terms of process, fostering the involvement of the whole team of the school members, developing strategic measures for ensuring success, and building school-community partnership (Davies, 2007; Hargreaves \& Fink, 2007; Epstein, Galindo, Sheldon, 2011).

\section{The Sample and The Procedure of the Study}

The study consists of two phases. The first phase includes electronic questioning of the school leaders on ESD in curriculum building, how schools pursue innovative practice and sustainable pedagogical approaches. The second phase of research includes a detailed analysis of case studies of two schools that succeeded in implementing sustainability agenda on the level of whole school policy in different ways.

The authors have carried out an electronic survey of the heads and the deputy heads of 26 UNESCO associated schools in Latvia, the response rate was 19 schools out of 26 inquired. As a result of this survey, two schools were identified as cases of good practice for integrating the idea of sustainability is school curricula and everyday practice. The devotion of the schools' administration to the idea of sustainability of those two schools has made both schools in different ways competitive and recognizable. One of the chosen schools has relatively new and enthusiastic staff members who are willing to create a collective knowledge. Their efforts result in successful collective action. This school is flexible in reviewing and renewing goals, structures and practices, if needed. The second school is known in the community as a school that works intensively on implementing inclusive policy for all children. The deputy head of this school holds a belief that all children can learn and believe in providing adequate learning challenges for learning. Both schools have similar goals and intentions though their structures and histories are different. If the first school is more of an elite school and is oriented to reach high achievements, simultaneously by preserving open culture of sustainability, the other school does not demonstrate such a high culture of academic achievements, though it is inclusive of children from different social, ethnic, cultural and language backgrounds. It sets a priority of developing social skills and a value system of learners, as well as demonstrates its potential for sustainability.

\section{Research Findings}

This survey of the leaders of UNESCO associated schools found that there is no universal formula to define sustainability. Instead, there are various definitions and contextualized interpretations of the term by the heads and the deputy heads of the schools. Diverse responses of the school leaders on integration of sustainability in schools allow the conclusion that the school leaders have a fuzzy understanding of what education for sustainable education is. Therefore, it is essential to understand this concept in its 
widest scope as an all-encompassing concept. Majority of school leaders pursue sustainability by emphasizing mostly its ecological dimension. 'While school administrators had a difficulty to define sustainability, they had no difficulty to identify what is unsustainable in the societies, like, inefficient use of energy, lack of natural resources, pollution, consumerism, etc. They lack a clear definition of sustainability. Particular emphases of electronic survey of school administrators was placed on such aspects, as educational purposes and aims informed by the ESD, innovative practice in schools, cooperation with multiple stakeholders and a curriculum development related to ESD.

\section{How can ESD Update and Question Traditional Perceptions of Quality and Better Outcomes?}

As it was responded by many heads of the schools that the aim of an education is quality education. "Schools should prepare the student for the requirements of a job market and to encourage them to live with a responsibility in everyday situations and in harmony with the environment"; to develop students' skills that enable them to find a solution in any situation. Many school leaders admitted that schools are trying their best to improve the outcomes of education by putting emphases not only on cognitive aspects of teaching but also on developing a spiritual part of a person who treats the surrounding world, people, and cultural heritage with sensitivity, care, and respect.

Some leaders of schools expressed a strong conviction that ESD aims to put its emphases on inclusive education, embracing the needs of all children and adding a value dimension to the educational aim. Many leaders defined an educated person as the one who is competitive in a job market and lives in harmony with oneself and a surrounding world. The aim of education set with an ESD perspective in mind puts an emphasis on the purpose rather than on the outcomes of formal learning process.

\section{How do ESD Help to Improve and Enrich School Curriculum Development in Your School?}

The curriculum puts more emphasis on the upbringing and value aspects in teaching. ESD improves curriculum by transforming it in a more integral and a holistic way. Many efforts have been made in this regards and a holistic and integrated view on a curriculum has been implemented at the kindergarten stage so far, though much has been left undone on the secondary school level. ESD can improve curriculum by integrating sustainability in all subject areas of education. Interdisciplinary and integrated reforms towards curriculum can foster creative thinking in the educational process what will lead to new ways of teaching and learning which still is a vision to be reached for many schools.

The heads of the UNESCO associated school have sketched the work to be done: So far, ESD is integrated into the curriculum in a very fragmented way. Though, it shouldn't be viewed as an add on subject but should be organically embedded throughout the whole curriculum. For example, "we cannot view an issue of sustainable lifestyle as a part of nature studies only, but it should be seen as an integral part of the whole school policy, reflected in both, formal and informal aspects of education in schools." As a desired ideal, pronounced by many school leaders, is inclusion of an ESD aspect in all curriculum subject areas with an emphasis on cognitive, emotional and spiritual dimensions in teaching. The work to be done as envisioned by many school leaders, is a 
reduction of standardization, placing more emphases on such values as respect of students' culture, well-being, and the needs of all students' abilities. They expressed the need to enrich curriculum by such ESD issues as tolerance, environmental issues, multicultural issues and cultural heritage more.

How do ESD Guide Students to Have the Knowledge, Skills and Values to Care for and Solve the Sustainable Development Issues that will Arise in Their Lifetime in Your School?

Re-orienting curriculum and school practice towards a more sustainable curriculum has never been an easy task (Hargreaves \& Fink, 2006; McKeown, 2002). Curriculum outcomes encompass knowledge, skills, values, and perspectives of the environmental, social, and economic aspects that comprise sustainability. The attempts to integrate sustainability issues into the curriculum as a rule are initiated by the enthusiastic administrators and very few teachers.

As seen by many school administrators, education for ESD is value-based education, focused on forming students' attitude towards the world, oneself and others, as well as building their understanding about the sustainable environment; involving them in sustaining and maintaining it.

ESD offers innovative educational content that allows students to acquire and to understand local and global processes; ESD develops students' respect for nature, other people and cultures; it teaches students to respect the viewpoints of people from different cultures, religions, social backgrounds and teaches them about what sustainability is in practice: about a sustainable life style and understanding of evils of consumerisms.

As the best practice mentioned by the school leaders, is that along with the academic knowledge, schools should teach values of tolerance towards diverse cultures and languages, as well as responsibility. Among the virtues taught are care towards the surrounding environment, support of a sustainable life style, issues of environmental protection, and conservation of natural resources. The school equips students with basic academic knowledge in all subject areas, as well as develops a sense of both local and global responsibility, anticipatory thinking; builds recognition of global interdependence, and interconnectedness.

A desired practice in building a curriculum, as mentioned by the school leaders, is teaching integrated and interconnected understanding of global ecological, economic, cultural changes that embrace values of sustainable development. This will allow one to find creative solutions to current global crises. Also, the curriculum needs to address an issue of pupils' consumption patterns more. Students of all age groups need to develop responsible attitudes towards the environment.

ESD fosters outreach to a local community and ensures a modernization of schools in all subject areas. It was expressed as a desirable idea to invite more quest speakers in schools who are professional on the issues of sustainability.

How do ESD Strengthen the Partnerships between Schools and Other Stakeholders, Including the Surrounding Community?

Education for ESD motivates students to participate in a community - outreach activities, and involves them actively in the community activities. Schools have established 
close cooperation with the local municipality. ESD fosters cooperation at all levels - in the classroom, cooperation of a school with families and the society. When students organize an event at school this is a common practice to involve pupils' parents and members from the society and other organizations. It fosters positive interrelatedness among all the actors involved. Among the events mentioned by the school leaders are: a week of animal protection, the day of cats, the day of planting trees, the day of health, meeting with the representatives of different professions, the day without any wasted paper, and the day of greeting.

Work to be done, as mentioned by the school leaders, is a development of close connectedness with a community by implementing inclusive policy at school. The community needs to be educated how to be inclusive to all people, otherwise the students with special needs when they complete school meet a harsh reality in the community that practices an exclusivist attitude. Implementation of an inclusive policy towards children with special needs, and creating a welcoming place for children from the community to join diverse activities that are taking place in schools, and is an achievement of many schools: "Our school has rich cultural traditions; therefore the school becomes an inviting place for the local community members. Other schools who participated in similar projects (for example, UNESCO schools' associated projects) invited our school to participate in various cultural events."

ESD with its innovative approach to problem solving cannot be isolated from the society and other educational establishments. Therefore, ESD fosters joint project initiatives, teacher mobility, and workshops. Schools' practice is enriched by cooperation with a local municipality and a community. Issues to be considered, as mentioned by the school leaders, are overcoming formal cooperation with a local community and making it more meaningful and orientated towards the aim of ESD. This may be explained by the lack of common goal. Society is becoming commercial and driven by the consumers' policy.

\section{How does ESD Promote Innovation in the Teaching-learning Conceptual Framework?}

With the regards to innovations in pedagogical practice, the school introduces new methods in teaching. Teachers choose teaching methods that motivate learners to use knowledge in practice. Innovative education in schools involves introducing new learning approaches, and methods of teaching carried out with a sustainability aim in mind. Innovations in education mean constructivism in teaching, self-directed learning, interrelatedness in curriculum, and meaningful learning experience. Some schools are open to innovative practice in a response to all changes that are taking place in the society. Innovative practice in many schools is implemented by designed new learning materials that respond to the diverse needs of all students, by developing new infrastructure that makes the environment open of the inclusion of children with special needs and opens opportunities for informal education.

Innovative practices introduced in schools encourage each and every teacher to search for new approaches and forms of teaching. Schools constantly re-evaluate and reshape educational content and methods. Teachers learn new technologies, search for new ways of modernization of schools, learn the experience of other schools, and new methodologies how to teach talented children. There are open and creative teachers, who understand the value of changes and progress, understand the interrelatedness of 
all things via exchange of personal experiences; they analyze changes in education and understand their position as change agents. This opens the ground for innovations in pedagogy and development of a cooperative culture at school.

This electronic survey allows us to discover a number of cases of good practice though an overall picture of sustainable development has been fuzzy and marginal, demonstrating a lack of shared understanding of a sustainable development. There was a considerable ambiguity in how school administrators interpreted a sustainable development. The increasing emphases of standard and standardization at schools have been mentioned as obstacles of implementing sustainability agenda in schools.

\section{Signs of Wise Leadership as Discovered in Two Cases of Good Practice}

The second part of the study reveals signs of wise leadership as discovered in the example of two schools of good practice in Latvia.

School Nr 1 is a relatively new school with young and enthusiastic staff members that has gained its high reputation in the community with the high academic achievement scores, innovative practice, strong emphases on value education and a culture of sustainability. This school's administration pursues a strategy of a participative decision making processes and has developed a commitment to an ecologically transformative culture at school. The school has developed caring and supportive community of learners. Particularly strong in this school is an ecological dimension of sustainability reached through the integration of it in the school's curriculum via science disciplines and informal learning. Most of the environmental projects, such as recycling, nature projects, and community based environmental educational projects, are carried out by the committed teachers and in the extracurricular activities out of deep passion. Political dimension of sustainability in this school has been practiced by developing a dialogical and democratic decision making processes among the administration and staff members. Each teacher has a voice in deciding upon the best ways of transforming the culture of school towards a more sustainable.

The leader of this school believes that ESD can improve educational purposes and outcomes by integrating values of sustainable development in all aspects of teaching. In this school, sustainability is not a matter of one discipline but it is integrated in many subject areas. Particular attention is paid to integrating an ecological dimension and learning environmental topics. All pupils are active participants of the learning process and they all are involved in decision making process over their learning. Teachers integrate locally relevant information, as well and make pupils aware of their responsibilities on a global scale.

The school has a good profile in facilitating collaboration of the school with families, local community and providing a platform for a dialogue between all the actors involved.

School practices project-based learning by actively involving pupils in discovery learning about the environmental pollution and environmental protection. The school involves pupils in a number of initiatives related to cleaning the surrounding and in science projects which are directly related to local environmental issues.

As reported by the deputy head of the school, ESD helps to improve and enrich the school's curriculum development by building interconnectedness between subject areas. As the deputy head has mentioned: "ESD guides our students to have the knowledge, skills and values to care for and solve their future sustainable development issues." By 
integrating environmental and social dimension of sustainability, we teach our pupils such values as respect towards other cultures, religions and viewpoints and practice those values, and make it as a whole school policy." The school builds pupils' intercultural skills by involving them in a number of international projects.

With the regard to innovative practice, school $\mathrm{Nr} 1$ has developed a culture of research where teachers accept their role as researchers who are involved in updating their qualification by learning the latest approaches and methods of teaching and introducing ICT technologies in teaching. Spiritual dimension is also seen as a significant part of this school's policy; therefore parents more often make a choice to choose this particular school for their children.

School Nr 2 does not demonstrate high results in test scores, but the school is successful in creating an accepting environment for children from the disadvantaged families, children with special needs who are not much included in other schools. Among them are the children from the low income and single parent families. Still, this school practices a political dimension of sustainability and is successful in organizing sociocultural and ecological changes towards a culture of learning sustainability. This school works towards designing a caring and creative all - inclusive culture at school. As it was reported by the administration of the school, teachers face a tension between the accountability of the school for the educational outcomes and a transformation of the school's culture towards sustainability. The school puts a particular emphasis in pursuing physical, emotional and spiritual health of their students. School teaches their students basic skills and work habits how to make wise choices for a sustainable future, both personal and global. Sustainability in this school is practiced in everyday activities, such as switching off lights when unnecessary, recycling paper, volunteering in the environmental projects, and others.

The administration of the school believes that ESD can update and improve educational purposes and outcomes by implementing inclusivity as a whole school approach where each and every child is valued and respected. Despite the discussions on the best models of inclusion of children with special needs in general education, schools and the society display a resistance to inclusive policy due to many subjective and objective factors. The school is searching for the best solutions to meet the needs of every child within the context of the whole school policy and to create an inclusive environment where all children have an access and where each child is a full and valued member of a school's community. As the school leader has mentioned: we do not demonstrate high academic achievement but we offer a welcoming learning environment for every child, we respect his/her cultural background and social status. We work with children who come to school from the low income and disadvantaged families, therefore we need to teach basic skills and build cooperation at all levels - with the municipality, with families, special pedagogues and other specialists"

"We believe that apart of academic knowledge we need to provide a strong value education. Value system will help our learners to build positive relations towards themselves, others, and the environments. To reach this aim, we use project work, constructivist approaches towards teaching, and practice hands on learning."

Both schools constantly renew their practices, and teachers perceive change as a part of their reality. There are some particular points that were singled out in both cases of good practice: the way both schools introduce innovations by respecting the past experience in schools, and the ways they introduce pedagogical approaches suitable for ESD. 


\section{Connecting Past, Present and Future for Introducing Innovative Practice}

As mentioned by the leaders of both schools, one of the signs of sustainability in school management is honoring and preserving the best of the past traditions in teaching and curriculum development, and then moving beyond the best of the past by introducing innovative practice in teaching. Abrahamson (2004) suggests a 'creative recombination' which combines the best of past experiences, renews it and creates something new (p. 10). Teachers tend to practice what is understandable and proved in practice, but the leaders of the school encourage their teachers to replace habitual ways of doing things with new learnings in a supportive way by furthering teachers' professional development. While introducing innovative practice, the interviewed school leaders perceive problems as opportunities for learning. They work in flexible teams. As one of the leaders has mentioned, "by introducing new practice we develop teachers' dispositions for taking risks and change rather than sticking to standardized instruction. We create the environment for continuous rather episodic teachers' further development and inquiry." Both schools adapt new technologies by integrating them in schools' practice. Sustainable leadership preserve the best from the past traditions, at the same time revisits memories and wisdom and values slow, thoughtful changes. Such schools avoid standardization that weakens adaptability an resilience.

\section{Sustainable Leadership Maintains Pedagogy and Strategies that Support ESD}

Both schools educate their students for the mandatory state tests and examination requirements, but still manage creating authentic learning environment for their children to succeed. The educational process is participatory, contextual and leading towards sustainable development. Both schools practice learner - centered pedagogical approaches that put an emphases on meaningful learning, constructivist learning, as well as on value education. Constructivist learning used in both schools puts a control over learning in hands of pupils, and teachers have a role of a facilitator. Both schools organize teaching as discovery learning. As stated by the DESD (2005-2014), schools need to put emphases on values and practices related to a sustainable development in education (UNESCO, 2010). Both selected schools support this initiative. They treat schools as living systems made of people who may choose to contribute or not to contribute to a well-being of school. Or, as Van der Heiden (1991) states, "schools are networks of individuals linked together through interconnections based on conversations" (p. 273). Leaders of both schools skillfully engage in strategic conversations.

\section{Pursuing Environmentally Sustainable Pedagogy and Approaches}

Schools labelled as an eco-school put high focus on environmental dimension of sustainability, which is in line with Orr (1994), who asserts that 'the goal of education is not about the mastery of subject matter, but subject matter is simply the tool' (p.13). The deputy head of the first school has emphasized the importance of meaningfulness of what students acquire and their understanding on how the acquired knowledge affects the world and other people. Knowledge building involves not only analytical, but also intuitive and spiritual knowing that is enriched by cultural and community identities. This eco-school puts emphases on studying traditions, culture, ecological knowledge 
that facilitates learner's social responsibility towards the others and the world. This grounds students in a local culture. Smith (2002) calls it "a place - based education" (p. 5) that grounds learning in local contexts and students' lived experience. The particular interest to integrate sustainability in science can be explained from the personal interest of the deputy head to bring innovative practice in school.

\section{Conclusions}

Sustainability more often is seen as desirable ideal and elusive phenomena, both in research literature and in the research part of this study. The leaders of many schools claimed that they recognize ecological and social aspect of sustainability in their practice. Sustainable development gradually becomes a part of curriculum and influences pupils' achievement. School leaders reported on how sustainability gradually became a part of meaning making processes in the school but this still requires the schools to see how all the initiatives fit together in a more holistic frame. Many schools began to view how sustainability could gradually become an umbrella of a whole school policy.

Sustainability must be enhanced in education with more concrete actions. Schools are required to have quality assurance to improve teaching and learning, based on continuous improvement and systematic thinking. The case study of two successful schools of implementing sustainability agenda reflects how integration of education for sustainable development helps to overcome the existing barriers and presents challenges. These schools reflect the examples how the sustainable leadership can facilitate in overcoming barriers of discipline restricted organizational structures, academic conservationism, traditions that tie schools to traditional modes of teaching, lack of interest and involvement of the staff members, overcrowded curriculum and pressure of time, obstacles more frequently mentioned by the leaders of the schools.

The second part of this study reflects the stories of two leaders of schools who share their experience of bringing improvement and innovations in their schools, fostering greater sustainability in their schools, building connections with a community. The evidence gained from two schools of good practice as identified in the community by the families and the school board, shows that the leaders of two schools contributed to the design of the schools' environment as a whole school approach. In both schools sustainability is contextualized as a shared whole school agenda by ensuring quality education. Both schools pay particular attention to an ecological and social dimension of sustainability, by giving attention to the social and ecological footprint they leave on local and global community. Sustainability in both schools gives an ethical framework to work within and provides a clear direction and purpose where the school is heading. By building the atmosphere of care, both schools contribute to the education of pupils into healthy and responsible citizens.

Sustainability in both schools characterizes a vision and values central of the policy of the school, with its emphasis on inclusive education, distributed approaches of leadership, as well as qualities of resilience and risk taking. Both schools undertake and initiate innovative approaches for teaching, such as inquiry and problem solving learning. Sustainable schools becomes venues of proving a rich learning environment to meet the needs of all children by providing the opportunity to work on tasks that have meaning and relevance to pupils. 
The leaders of both schools demonstrated a commitment to the development of a culture of a sustainable school, they understand the systemic nature of an organization, they are practical and hands on doers, see their concerns in different scale, they enable and share leadership rather than control power relations. They hold sustainability values that allow them to work within the deeper purpose.

\section{References}

Abrahamson, E. (2004). Change without pain: How managers can overcome initiative overload, organizational chaos, and employee burnout. Boston: Harvard Business School Press.

Ballard, D. (2005). Using learning processes to promote change for sustainable development. Action Research, 3(2), 135-156. doi: 10.1177/1476750305052138

Cameron. K. S., \& Quinn, R.E. (2006). Diagnosing and changing organizational culture. Based on the competing values framework. Boston: Addison Wesley Longman Inc.

Epstein, J. L., Galindo, C. L., \& Sheldon, S. B. (2011). Levels of leadership effects of district and school leaders on the quality of school programs of family and community involvement. Educational Administration Quarterly, 47(3), 462-495.

Schein, E. H. (2004). Organizational culture and leadership (3 ${ }^{\text {rd }}$ ed.). SanFrancisco: Jossey-Bass.

Davies, B. (2006). Leading strategically focused school. London: Paul Chapman Publishing.

Davies, B. (2007). Developing sustainable leadership. Sage: Paul Chapman Publishing.

Duignan, P., \& Bezzina, M. (2006, October). Distributed leadership: The theory and practice. Paper presented at the CCEAM Annual Conference, Lefkosia, Cyprus.

Hargreaves, A., \& Fink, D. (2007). Energizing leadership for sustainability. In B. Davies (Ed.), Developing sustainable leadership. London: Paul Chapman Publishing.

Held, P. (2011). Implementing e-learning and e-examination in European universities: Factors of success. Proceedings of International Conference on the Future of Education (pp. 116-120). Florence: Simonelli Editore University Press.

Hepburn, A., \& Potter, J. (2007). Discourse analytic practice. In C. Seale, G. Gobo, J. F. Gubrium \& D. Silverman (Eds.), Qualitative research practice (pp.168-183). London: Sage.

Holm, T., Sammalisto, K., Grindstead, T. S., \& Vuorisalo, T. (2015). Process framework for identifying sustainability aspects in university curricula and integrating education for sustainable evelopment. Journal of Cleaner Production, 1-11.

Iliško, Dz., Skrinda, A., \& Mičule, I. (2014). Envisioning the future: Bachelor's and Master's degree students' perspectives. Journal of Teacher Education for Sustainability, 16(2), 88-102.

Mc Keown, R. (2002). Education for sustainable development. Toolkit - Version 2.0. Retrieved from http://www.esdtoolkit.org/default.htm

Orr, D. W. (1994). Earth in mind: On education, environment, and the human prospect. Washington, DC: Island Press.

Scott, W. (2013). Developing the sustainable school: thinking the issues through. The Curriculum Journal, 24(2), 181-205.

Smith, G. A. (2002). Place-based education: Learning to be where we are. Retrieved 12 December, 2014, from:http:/www.library.wmich.edu:2028/images/WSPL/wsppdfl/ HTML/01226.M32MZ/83B 
Stemler, S. (2001). An overview of content analysis. Retrieved September 30, 2011, from http://PAREonline.net/getvn.asp?v=7\&n=17

Sterling, S. (2005). Linking thinking: New perspectives on thinking and learning for sustainability. In S. Sterling, D. Irvine, P. Maiteny \& J. Salter (Eds.), Linking thinking - new perspectives on thinking and learning for sustainability (pp. 5684).WWF: Scotland.

UNESCO. (2004). Education for all. The quality imperative. Available from http://unesdoc.unesco.org/images/0013/001373/137333e.pdf

UNESCO. (2005). International implementation scheme and UNESCO. Contribution to the implementation of Decade. Paris: UNESCO.

UNESCO. (2006). Education for sustainable development toolkit. Paris: UNESCO.

UNESCO. (2010). Education for sustainable development. Retrieved July 15, 2013, from http://unesco.org/en/esd/

UNESCO (2015). Shaping the future we want. UN Decade of Education for Sustainable Development (2005-2014). Available from http://unesdoc.unesco.org/images/0023/ 002303/230302e.pdf

Van der Heiden (1996). Scenarios - the art of strategic conversations. New York: Wiley. Wood, L. A., \& Kroger, R. O. (2000). Doing discourse analysis: Methods for studying action in talk and text. London: Thousand Oaks. 